\title{
Experimental Characterization of Advanced Materials for the Catalytic Decomposition of Hydrogen Peroxide
}

\author{
Cristina Bramanti* \\ ESA-ESTEC, Keplerlaan 1, Nordwijk, The Netherlands \\ Angelo Cervone ${ }^{\dagger}$, Luca Romeo ${ }^{\ddagger}$, Lucio Torre ${ }^{\S}$, Luca d'Agostino ${ }^{* *}$ \\ ALTA S.p.A. - Via Gherardesca, 5 - 56121 Ospedaletto, Pisa, Italy \\ Antony J. Musker ${ }^{\dagger \dagger}$ \\ DELTACAT Ltd., White Lodge-Ryde Place, Lee on Solent, England \\ and \\ Giorgio Saccoccia \\ ESA-ESTEC, Keplerlaan 1, Nordwijk, The Netherlands
}

\begin{abstract}
Alta S.p.A. (Italy) and DELTACAT Ltd. (United Kingdom) are conducting a study, funded by the European Space Agency, into the development of hydrogen peroxide monopropellant thrusters using advanced catalytic beds. The present paper focuses on the design of a dedicated test bench to assess the effectiveness of different catalyst samples when immersed in hydrogen peroxide. To date, the apparatus has been used to study powdered silver and three oxides of manganese. The evaluation of an analytical technique for determining the observed decomposition rates is also presented. In addition to devising a quantitative method for assessing the efficacy of the candidate catalysts, some qualitative studies of proposed metallic catalysts, in the form of wires immersed in hydrogen peroxide, are also described. Of the catalyst materials tested so far, preliminary results suggest that dimanganese trioxide offers slightly better performance than both manganese dioxide and silver.
\end{abstract}

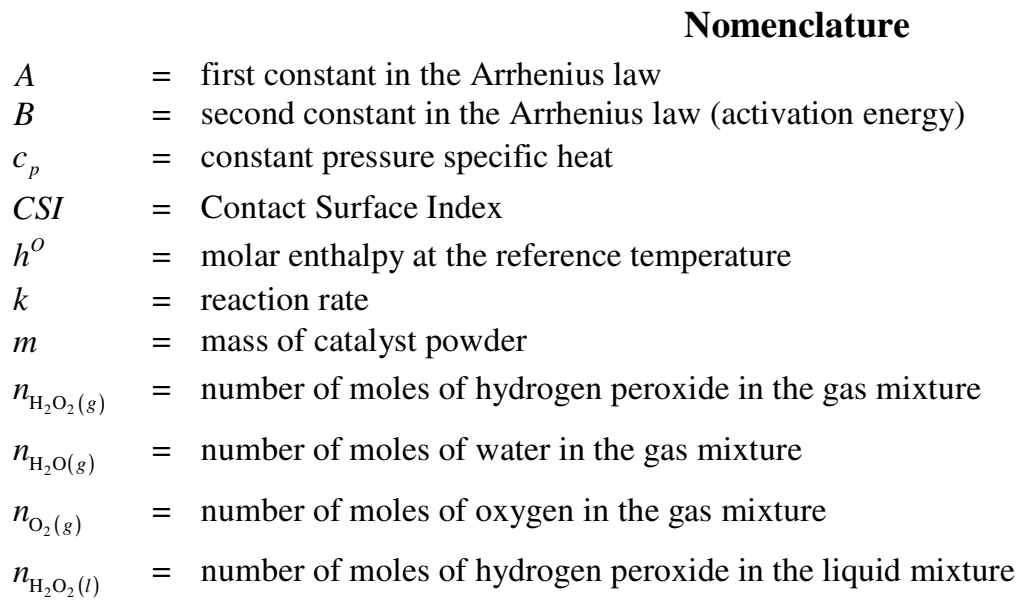

\footnotetext{
*Post-Doc Fellow, ESA Advanced Concepts Team, AIAA member; Cristina.Bramanti@ esa.int.

${ }^{\dagger}$ Project manager, ALTA S.p.A., AIAA Member; a.cervone@ alta-space.com.

${ }^{\ddagger}$ Ms. Student, Department of Aerospace Engineering - University of Pisa.

${ }^{\S}$ Project engineer, ALTA S.p.A., AIAA Member; 1.torre@alta-space.com.

${ }^{* * *}$ Professor, Department of Aerospace Engineering - University of Pisa, AIAA Member; luca.dagostino@ing.unipi.it.

${ }^{\dagger}$ Director, DELTACAT Ltd., AIAA Member; tony.musker@ deltacatuk.com.

${ }^{\sharp}$ Head of Propulsion \& Aerothermodynamics Division, ESA-ESTEC, AIAA Member; Giorgio.Saccoccia@ esa.int.
} 


$$
\begin{array}{ll}
n_{\mathrm{H}_{2} \mathrm{O}(l)} & =\text { number of moles of water in the liquid mixture } \\
n_{\mathrm{O}_{2}(l)} & =\text { number of moles of oxygen in the liquid mixture } \\
\dot{n}^{(e)} & =\text { molar flux from the main bottle to the exhaust duct } \\
\dot{n}^{(i)} & =\text { molar flux from the liquid mixture to the main bottle } \\
\dot{n}^{(r)} & =\text { molar reaction rate } \\
r & =\text { mean radius of powder grains } \\
R & =\text { universal gas constant } \\
\rho & =\text { density of catalyst powder } \\
T_{a} & =\text { adiabatic decomposition temperature } \\
T_{p} & =\text { gas mixture temperature in the main bottle } \\
T_{r} & =\text { liquid mixture temperature } \\
T^{O} & =\text { reference temperature }
\end{array}
$$

Subscripts:

$\begin{array}{ll}(g) \quad & =\text { gaseous state } \\ (l) & =\text { liquid state }\end{array}$

\section{Introduction}

T $\mathrm{N}$ recent years low-toxicity storable liquid propellants have become considerably more attractive as possible 1 substitutes for nitrogen oxides and hydrazines. The main benefit of these alternative propellants is the significant cost saving associated with the drastic simplification of the health and safety protection procedures necessary during propellant production, storage and handling.

One of the most known low-toxicity liquid propellants is hydrogen peroxide, which has also played a significant historical role as the first propellant used for rocket vehicles. A significant amount of work has been carried out in the 1960s by NASA laboratories concerning hydrogen peroxide decomposition and its application to monopropellant rockets ${ }^{1,2}$ but this effort was subsequently abandoned. Over the last decade interest in hydrogen peroxide has been renewed. Hydrogen peroxide is now seen as a promising propellant for liquid propellant engines and many detailed studies have been conducted ${ }^{3,4,5,6}$. The use of catalysts or catalytic beds is historically considered the best way of accomplishing the decomposition of hydrogen peroxide, as thermal decomposition is usually much slower than catalytic decomposition. Several experimental investigations have been undertaken to evaluate various catalyst materials for the decomposition of hydrogen peroxide at high concentration, in order to develop a catalytic bed with high activity and stability, low weight and low cost ${ }^{3,7}$.

The earliest catalytic beds for high-concentration hydrogen peroxide solutions (up to 98\%), realized in the 1950s and 1960s, were based on the principle of using different materials, like high melting point silver alloys (silver palladium), platinum, palladium, iridium, ruthenium, manganese dioxide, cobalt. However, no one of these candidate materials provided adequate performance. More recently, General Kinetics in the United States claims to have developed several different catalytic beds, the most interesting of which used manganese dioxide pellets $\left(\right.$ Ventura \& Wernimont ${ }^{8}$ ). These catalytic beds were proven to decompose more than $10000 \mathrm{lb}$ of propellant during their life. Also flight qualified versions of $98 \%$ HP catalytic beds are claimed to have been realized, but no information is provided on their characteristics.

A particularly interesting experimental activity for the characterization of catalytic materials has been carried out by Rusek ${ }^{9}$ at the US Edwards Air Force Base in California. The experiments were conducted in a constant-volume batch reactor, on test items obtained by impregnation and calcination of alumina or silica-alumina spheres with several different materials. In the tests, all the manganese oxides showed a similar relative activity, not affected by the addition of a base promoter to manganese (i.e. potassium). Silver oxide was, quite surprisingly, one of the least active catalysts. Another set of tests showed that platinum on alumina is a very active catalyst, followed by manganese oxides. The least active catalysts were found to be samarium-promoted silver screens, i.e. the conventional peroxide decomposition catalysts.

Pirault-Roy et al. ${ }^{10}$ performed a wide experimental activity at the University of Poitiers, in collaboration with CNES, on the determination of the order of reaction of different catalyst materials and the study of the influence of stabilizing agents contained in commercial hydrogen peroxide on the catalytic activity. In this case, the catalyst with 
the highest catalytic activity seemed to be silver, followed by manganese oxides and platinum. Iridium and platinum-tin alloy showed a worse performance. The catalytic activity of both silver and manganese oxides decreased, as expected, when pyrophosphates were added to the propellant as stabilizers. Conversely, the addition of stannates caused, quite surprisingly, an increase in catalytic activity of the supported silver sample, while it had no influence on the activity of the manganese oxide sample.

As a direct consequence of the renewed interest in the use of hydrogen peroxide by the rocket propulsion community, Alta S.p.A. (Italy) and DELTACAT Ltd. (United Kingdom) are carrying out an activity for the development of hydrogen peroxide monopropellant thrusters based on the use of advanced catalytic beds. This activity is funded by the European Space Agency in the framework of the LET-SME program, related to innovative projects carried out by small and medium European companies. The objective of the activity is the design and realization of two prototype thrusters (a $5 \mathrm{~N}$ and a $25 \mathrm{~N}$ one), in which catalytic beds made of different catalyst materials and substrates will be installed and validated.

The present paper will illustrate the design of a dedicated test bench specifically intended for testing different catalyst samples and its validation by means of a set of experiments on powders. An analytical technique for the determination of the decomposition rate starting from the experimental results obtained in the test bench will also be presented and evaluated. The results of some qualitative "visual" tests on different metallic wires will finally be illustrated.

\section{Test Bench}

A specific test bench has been designed and realized by Alta for experimental evaluation of the catalytic activity of different materials. The choice of the working principle and of the other main characteristics of the experimental apparatus have been driven by the following requirements:

- Possibility of evaluating the reaction rate by means of temperature, pressure and/or flow rate measurements;

- $\quad$ Reduction of the costs for the realization of the test bench and for the experimentation;

- Capability of testing a wide range of different catalyst materials and geometries;

- Ease of utilization;

- Safety for operators.

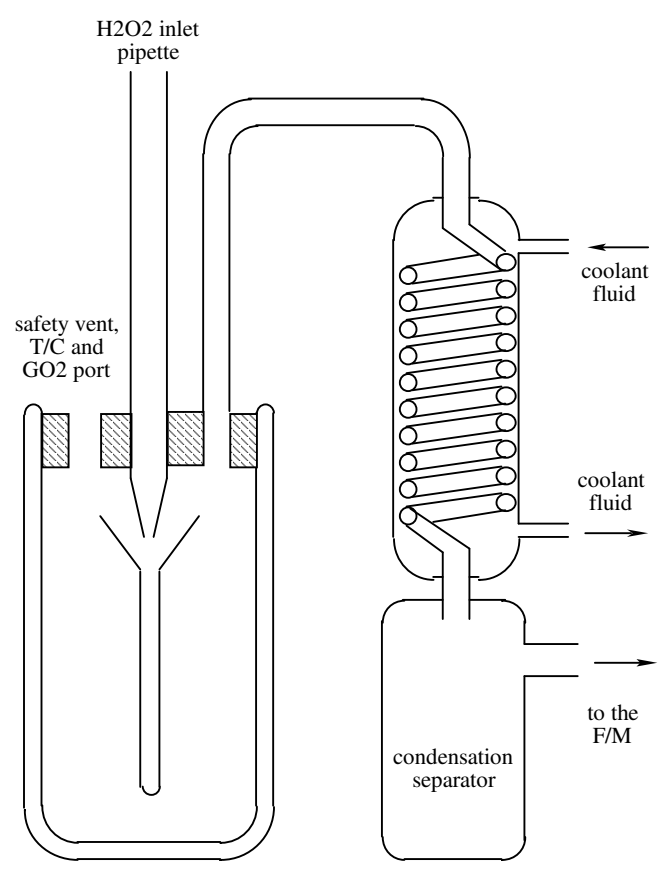

Figure 1. Schematic of the test bench.
As a consequence of the above requirements, the test bench has been designed following the conceptual scheme presented in Figure 1.

A known mass of the catalyst to be tested is inserted in a graduated tube, installed into a larger volume bottle. The upper part of the bottle is closed by means of a plug, in which some ports are present:

- A connection for the $\mathrm{H}_{2} \mathrm{O}_{2}$ inlet pipette;

- Two thermocouple taps, one for the measurement of liquid $\mathrm{H}_{2} \mathrm{O}_{2}$ temperature and the other for measurement of the gas temperature;

- A connection for the installation of a calibrated safety vent valve and for eventual pressurization of the bottle before the experiment;

- A port for exhausting the hot gas generated by the reaction..

After a given quantity of hydrogen peroxide solution is dropped into the graduated tube, the decomposition reaction promoted by the catalyst generates a hot gas mixture in which oxygen, steam and a small quantity of gaseous hydrogen peroxide are present. These gases are delivered through the exhaust port and enter a coil heat 
exchanger, in which their temperature is lowered by means of a cold liquid flow. The heat exchanger has been designed in order to assure condensation of all the steam in the gaseous mixture. The steam is therefore turned into water, collected in a condensation separator. As a consequence, the gas flow exiting from the heat exchanger is just gaseous oxygen and the flow rate, measured by means of a flow meter, can be directly correlated to the rate of reaction.

In the final design the main bottle is a glass cylinder with a volume of about 2 liters. The upper part of the bottle is closed by means of a glass plug clamped on it and sealed with a rubber o-Ring. The heat exchanger has an external diameter equal to $100 \mathrm{~mm}$ and the length of the coil is $1 \mathrm{~m}$, with a coil diameter of $8 \mathrm{~mm}$. The glass condensation separator has a diameter of $100 \mathrm{~mm}$ and a length of $100 \mathrm{~mm}$. All the connections are made by means of flexible rubber hoses.

Temperature measurements are carried out by means of K-type thermocouples with a diameter of $1.5 \mathrm{~mm}$ and a length of $250 \mathrm{~mm}$. The thermocouples are coated with stainless steel, in order to provide protection against oxidation. The flow meter chosen for the test bench is a thermal mass flow meter produced by Bronkhorst Hi-Tec, model F112AC-ABA-00-V-MFM.

\section{Analytical Model of the Test Bench}

The test bench design and the preliminary evaluation of its performance have been carried out using a simplified analytical model. This model has also been used for evaluating the decomposition reaction rates starting from the test results, as it will be described in the following. The model is characterized by separate analytical evaluations of the decomposing liquid mixture and the gas in the main bottle.

The main initial assumptions for the model are:

- $\quad$ liquid mixture temperature $T_{r}$, gas mixture temperature in the main bottle $T_{p}$ (assumed uniform);

- complete decomposition, based on the following reaction:

$$
\mathrm{H}_{2} \mathrm{O}_{2} \rightarrow \mathrm{H}_{2} \mathrm{O}+\frac{1}{2} \mathrm{O}_{2}
$$

- completely flooded catalyst.

Starting from the above assumptions, the adiabatic decomposition temperature $T_{a}$ can be easily calculated, as a function of the initial temperature, using the usual enthalpy balance equation. Furthermore, the following relation can be written between the molar reaction rates of water, oxygen and hydrogen peroxide:

$$
\dot{n}_{\mathrm{H}_{2} \mathrm{O}}^{(r)}=2 \dot{n}_{\mathrm{O}_{2}}^{(r)}=\dot{n}_{\mathrm{H}_{2} \mathrm{O}_{2}}^{(r)}
$$

The behavior of the decomposing liquid mixture is characterized assuming thermal equilibrium between gas and liquid, negligible oxygen dissolution and negligible heat losses. Under these assumptions, three molar balance equations can be written:

$$
\begin{gathered}
\frac{d n_{\mathrm{H}_{2} \mathrm{O}_{2}(l)}}{d t}=-\dot{n}_{\mathrm{H}_{2} \mathrm{O}_{2}}^{(r)}-\dot{n}_{\mathrm{H}_{2} \mathrm{O}_{2}(g)}^{(i)} \\
\frac{d n_{\mathrm{H}_{2} \mathrm{O}(l)}}{d t}=\dot{n}_{\mathrm{H}_{2} \mathrm{O}}^{(r)}-\dot{n}_{\mathrm{H}_{2} \mathrm{O}(g)}^{(i)}=\dot{n}_{\mathrm{H}_{2} \mathrm{O}_{2}}^{(r)}-\dot{n}_{\mathrm{H}_{2} \mathrm{O}(g)}^{(i)} \\
\frac{d n_{\mathrm{O}_{2}(l)}}{d t}=\dot{n}_{\mathrm{O}_{2}}^{(r)}-\dot{n}_{\mathrm{O}_{2}(g)}^{(i)}=\frac{1}{2} \dot{n}_{\mathrm{H}_{2} \mathrm{O}_{2}}^{(r)}-\dot{n}_{\mathrm{O}_{2}(g)}^{(i)}=0
\end{gathered}
$$

where $n_{\mathrm{H}_{2} \mathrm{O}_{2}(l)}, n_{\mathrm{H}_{2} \mathrm{O}(l)}$ and $n_{\mathrm{O}_{2}(l)}$ are, respectively, the number of moles of hydrogen peroxide, water and oxygen in the liquid mixture (the last one is zero as a consequence of the negligible oxygen dissolution assumption). On the 
other hand, $\dot{n}_{\mathrm{H}_{2} \mathrm{O}_{2}(g)}^{(i)}, \dot{n}_{\mathrm{H}_{2} \mathrm{O}(g)}^{(i)}$ and $\dot{n}_{\mathrm{O}_{2}(g)}^{(i)}$ are the molar fluxes of gaseous hydrogen peroxide, steam and oxygen from the liquid mixture to the main bottle. These molar fluxes can be easily written as functions of $n_{\mathrm{H}_{2} \mathrm{O}_{2}(l)}, n_{\mathrm{H}_{2} \mathrm{O}(l)}$ and the vapor pressures of water and hydrogen peroxide, which in turn are functions of the liquid mixture temperature.

Together with equations (3), (4) and (5), the following molar energy balance can be written for the liquid mixture:

$$
\begin{gathered}
\frac{d}{d t}\left\{n_{\mathrm{H}_{2} \mathrm{O}_{2}(l)}\left[h_{\mathrm{H}_{2} \mathrm{O}_{2}(l)}^{\circ}+c_{p \mathrm{H}_{2} \mathrm{O}_{2}(l)}\left(T_{r}-T^{\circ}\right)\right]+n_{\mathrm{H}_{2} \mathrm{O}(l)}\left[h_{\mathrm{H}_{2} \mathrm{O}(l)}^{\circ}+c_{p \mathrm{H}_{2} \mathrm{O}(l)}\left(T_{r}-T^{\circ}\right)\right]\right\}= \\
=-\dot{n}_{\mathrm{H}_{2} \mathrm{O}_{2}}^{(r)}\left[h_{\mathrm{H}_{2} \mathrm{O}_{2}(l)}^{\circ}+c_{p \mathrm{H}_{2} \mathrm{O}_{2}(l)}\left(T_{r}-T^{\circ}\right)\right]-\dot{n}_{\mathrm{H}_{2} \mathrm{O}_{2}(g)}^{(i)}\left[h_{\mathrm{H}_{2} \mathrm{O}_{2}(g)}^{\circ}+c_{p \mathrm{H}_{2} \mathrm{O}_{2}(g)}\left(T_{r}-T^{\circ}\right)\right]+ \\
+\dot{n}_{\mathrm{H}_{2} \mathrm{O}}^{(r)}\left[h_{\mathrm{H}_{2} \mathrm{O}(g)}^{\circ}+c_{p \mathrm{H}_{2} \mathrm{O}(g)}\left(T_{a}-T^{\circ}\right)\right]-\dot{\mathrm{H}}_{\mathrm{H}_{2} \mathrm{O}(g)}^{(i)}\left[h_{\mathrm{H}_{2} \mathrm{O}(g)}^{\circ}+c_{p \mathrm{H}_{2} \mathrm{O}(g)}\left(T_{r}-T^{\circ}\right)\right]+ \\
+\dot{n}_{\mathrm{O}_{2}}^{(r)}\left[h_{\mathrm{O}_{2}(g)}^{\circ}+c_{p \mathrm{H}_{2} \mathrm{O}(g)}\left(T_{a}-T^{\circ}\right)\right]-\dot{n}_{\mathrm{O}_{2}(g)}^{(i)}\left[h_{\mathrm{O}_{2}(g)}^{\circ}+c_{p \mathrm{O}_{2}(g)}\left(T_{r}-T^{\circ}\right)\right]
\end{gathered}
$$

where $T^{O}$ is the reference temperature, $h^{O}$ are the molar enthalpies of the different gaseous and liquid components at the reference temperature and $c_{p}$ are their constant pressure specific heats.

The gas mixture in the main bottle can be characterized using a similar procedure, assuming uniform pressure and temperature and negligible heat losses. The following molar balance equations can be written:

$$
\begin{aligned}
\frac{d n_{H_{2} O_{2}(g)}}{d t} & =\dot{n}_{H_{2} O_{2}(g)}^{(i)}-\dot{n}_{H_{2} O_{2}(g)}^{(e)} \\
\frac{d n_{H_{2} O(g)}}{d t} & =\dot{n}_{H_{2} O(g)}^{(i)}-\dot{n}_{H_{2} O(g)}^{(e)} \\
\frac{d n_{O_{2}(g)}}{d t} & =\dot{n}_{O_{2}(g)}^{(i)}-\dot{n}_{O_{2}(g)}^{(e)}
\end{aligned}
$$

where $n_{\mathrm{H}_{2} \mathrm{O}_{2}(g)}, n_{\mathrm{H}_{2} \mathrm{O}(g)}$ and $n_{\mathrm{O}_{2}(g)}$ are, respectively, the number of moles of hydrogen peroxide, water and oxygen in the gas mixture, $\dot{n}_{\mathrm{H}_{2} \mathrm{O}_{2}(g)}^{(g)}, \dot{n}_{\mathrm{H}_{2} \mathrm{O}(g)}^{(e)}$ and $\dot{n}_{\mathrm{O}_{2}(g)}^{(e)}$ are the molar fluxes of gaseous hydrogen peroxide, steam and oxygen from the main bottle to the exhaust duct. These molar fluxes can be written as functions of the exhaust velocity, which in turn is a function of the pressure and temperature of the gas mixture in the main bottle.

The molar energy balance for the gas mixture can be written in the following way:

$$
\begin{gathered}
\frac{d}{d t}\left[\left(n_{H_{2} O_{2}(g)} c_{p H_{2} O_{2}(g)}+n_{H_{2} O(g)} c_{p H_{2} O(g)}+n_{O_{2}(g)} c_{p O_{2}(g)}\right) T_{p}\right]= \\
=\left(\dot{n}_{H_{2} O_{2}(g)}^{(i)} c_{p H_{2} O_{2}(g)}+\dot{n}_{H_{2} O(g)}^{(i)} c_{p H_{2} O(g)}+\dot{n}_{O_{2}(g)}^{(i)} c_{p O_{2}(g)}\right) T_{r}+ \\
-\left(\dot{n}_{H_{2} O_{2}(g)}^{(e)} c_{p H_{2} O_{2}(g)}+\dot{n}_{H_{2} O(g)}^{(e)} c_{p H_{2} O(g)}+\dot{n}_{O_{2}(g)}^{(e)} c_{p O_{2}(g)}\right) T_{p}
\end{gathered}
$$

The equations (3), (4), (6), (7), (8), (9), (10), after suitable manipulation, give a system of 7 differential equations with 7 unknowns: $T_{r}, T_{p}, n_{\mathrm{H}_{2} \mathrm{O}_{2}(l)}, n_{\mathrm{H}_{2} \mathrm{O}(l)}, n_{\mathrm{H}_{2} \mathrm{O}_{2}(g)}, n_{\mathrm{H}_{2} \mathrm{O}(g)}$ and $n_{\mathrm{O}_{2}(g)}$. After having assumed a suitable law for the 
reaction rates $\dot{n}_{\mathrm{H}_{2} \mathrm{O}}^{(r)}, \dot{n}_{\mathrm{O}_{2}}^{(r)}$ and $\dot{n}_{\mathrm{H}_{2} \mathrm{O}_{2}}^{(r)}$ (usually as functions of the liquid mixture temperature), this system can be solved numerically in order to completely characterize the behavior of the test bench.

\section{Experimental results}

Two different sets of experiments have been conducted in the framework of the present activity:

- $\quad$ experiments on powders, carried out in the test bench described in Section II;

- qualitative tests on metallic wires, with visual characterization of the behavior of different sample wires after dropping a small quantity of hydrogen peroxide on them.

The visual tests on metallic wires have been carried out in parallel by Alta and DELTACAT, using a similar procedure. The results of tests on powders have also been used for estimating their decomposition reaction rate as a function of the liquid mixture temperature and the contact surface, as described in the following.

The hydrogen peroxide solution used for the experiments is the Riedel-de Haen PERDROGEN ${ }^{\circledR}$ (provided by Sigma-Aldrich), a 30\% concentration solution with a particularly low content of impurities and stabilizers like phosphates.

\section{A. Tests on powders}

The following powders have been tested in the framework of the present project:

- Silver powder, -60 mesh, 99.99\% purity;

- Manganese oxide (MnO) powder, -60 mesh, 99\% purity;

- Dimanganese trioxide $\left(\mathrm{Mn}_{2} \mathrm{O}_{3}\right)$ powder, -325 mesh, $99 \%$ purity;

- Manganese dioxide $\left(\mathrm{MnO}_{2}\right)$ powder, 60-230 mesh, 99\% purity.

The experiments have been conducted using the following procedure:

1. Insertion of the required mass of powder in the graduated tube of the test bench;

2. Preparation of the test bench and, in particular, of the fluid and electrical connections;

3. Dropping in the graduated tube a given quantity of hydrogen peroxide solution by means of the inlet pipette;

4. Continuous acquisition of the following quantities during the decomposition reaction:

- Temperature of the liquid mixture;

- Temperature of the gas mixture;

- Exhaust mass flow of gaseous oxygen;

5. Termination of the acquisition procedure after the completion of hydrogen peroxide decomposition.

The volume of hydrogen peroxide used for the experimentation has been the same $(5 \mathrm{ml})$ for all the tests. The time history of the liquid mixture temperature and the mass flow rate during a typical test appears as shown in Figure 2, referred to a test carried out on $20 \mathrm{mg}$ of $\mathrm{Mn}_{2} \mathrm{O}_{3}$ powder.

The liquid mixture temperature tends to increase up to about $100{ }^{\circ} \mathrm{C}$, when the decomposition reaction comes to completion. A slight increase in gas mixture temperature is observed when liquid mixture temperature reaches its maximum. This increase is more significant in experiments when the increase of liquid mixture temperature is faster. After the two temperatures reach their peak value, the reaction becomes very fast and the residual hydrogen peroxide decomposes in few seconds. When decomposition is completed, no more energy is generated and liquid and gas temperatures slowly decrease down to room temperature.

The exhaust mass flow of gaseous oxygen is practically zero during the first phase of the decomposition reaction, but shows a significant peak when the liquid mixture temperature begins to increase in a faster way. This increase of the mass flow rate of gaseous oxygen is strictly related to the increase of the reaction rate at increased temperature.

Figure 3 shows the typical appearance of the reactant mixture during the phase of faster increase of the liquid temperature: the generation of decomposition gases on the top of the graduated tube is evident. 

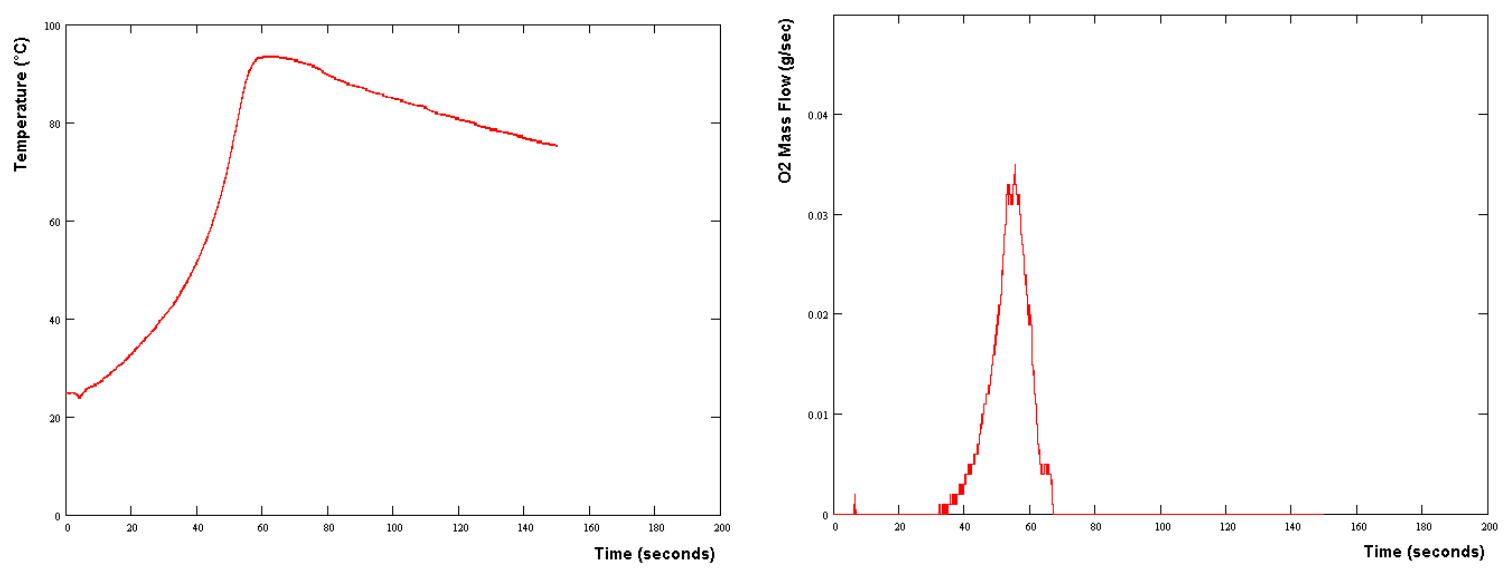

Figure 2. Time histories of the liquid mixture temperature (left) and the exhaust mass flow of gaseous oxygen (right) during a test on $\mathrm{Mn}_{2} \mathrm{O}_{3}$ powder (20 mg total mass) .

One important aspect taken into account in the evaluation of the experimental results is that the effective contact surface can be different from case to case, even if the same mass of powder is used. The effective contact surface depends on the mass of powder, the material density, the powder mesh and the geometry of grains. If the grains are assumed spherical, a comparative evaluation of the contact surface can be made using a Contact Surface Index (CSI), defined as:

$$
\mathrm{CSI}=\frac{3 m}{\rho r}
$$

where $m$ is the powder mass, $\rho$ is the material density and $r$ is the mean particle radius (dependant on the powder mesh). For the present experimentation, two tests carried out at the same value of CSI have been considered equivalent by the point of view of the contact surface. It has to be noted that the "spherical grains" assumption can be significantly far from the real grain geometry; nevertheless, the CSI parameter defined as above can represent a good index for a comparative evaluation of catalyst powders, at least at a first preliminary stage.

The catalytic activity of the different powders has been compared by means of two parameters: the time needed to reach the peak value of liquid mixture temperature and the peak value of exhaust mass flow of gaseous oxygen (see Figure 2). Comparative plots of these two quantities as a function of the CSI index, for the different powders used during the experimentation, are given in Figure 4 and Figure 5. In these two figures the single points represent the experimental values and the dashed lines are

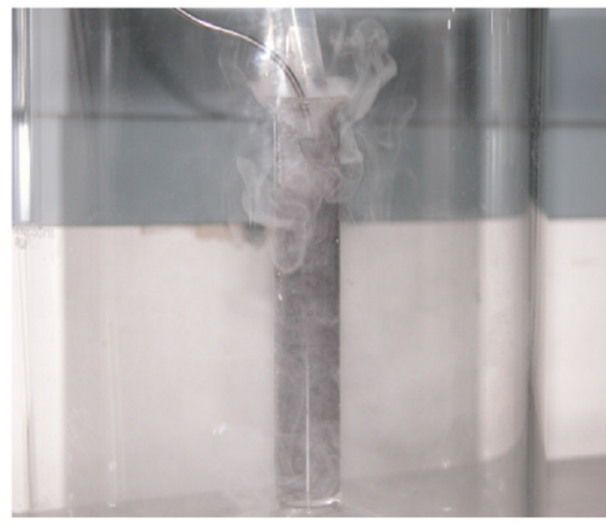

Figure 3. Typical appearance of the reactant mixture during a test $\left(\mathrm{Mn}_{2} \mathrm{O}_{3}\right.$ powder, mass $=20 \mathrm{mg}$ ). obtained by a best fit of the experimental data. In particular, the best fit of the time needed to reach the peak temperature value has been shown to be an exponential function of CSI, while the peak value of the mass flow of gaseous oxygen has been shown to be a linear function of CSI.

Analysis of Figure 4 and Figure 5 shows that the most active catalytic material seems to be $\mathrm{Mn}_{2} \mathrm{O}_{3}$, followed by Silver and $\mathrm{MnO}_{2}$ (the last two show a very similar catalytic activity) and, as the less active material, $\mathrm{MnO}$. 
In particular, tests on dimanganese trioxide $\left(\mathrm{Mn}_{2} \mathrm{O}_{3}\right)$ showed a significantly better performance with respect to the other three materials tested. It has to be understood if this difference is due to a real effectiveness of this material in accelerating the decomposition of hydrogen peroxide or, conversely, to an effect of the different mesh of the $\mathrm{Mn}_{2} \mathrm{O}_{3}$ powder tested. The assumption of spherical grains used for the evaluation of the CSI index, as stated above, could be more or less realistic depending on the mesh and the shape of the grains. In any case, however, the difference between the performance of $\mathrm{Mn}_{2} \mathrm{O}_{3}$ and that of the other powders seems to be too significant to be explained just by an incorrect evaluation of the contact surface. Therefore it can be assessed that this form of manganese oxide has probably a better catalytic action than the other materials tested.

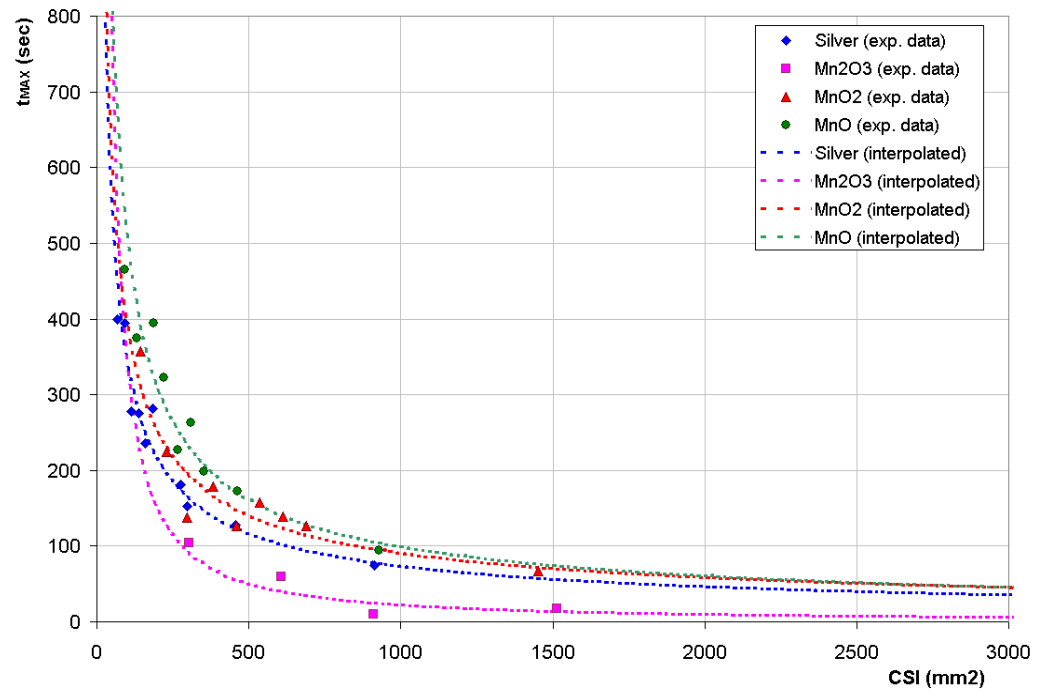

Figure 4. Time needed by the liquid mixture to reach the peak temperature, as a function of CSI, for four different powders.

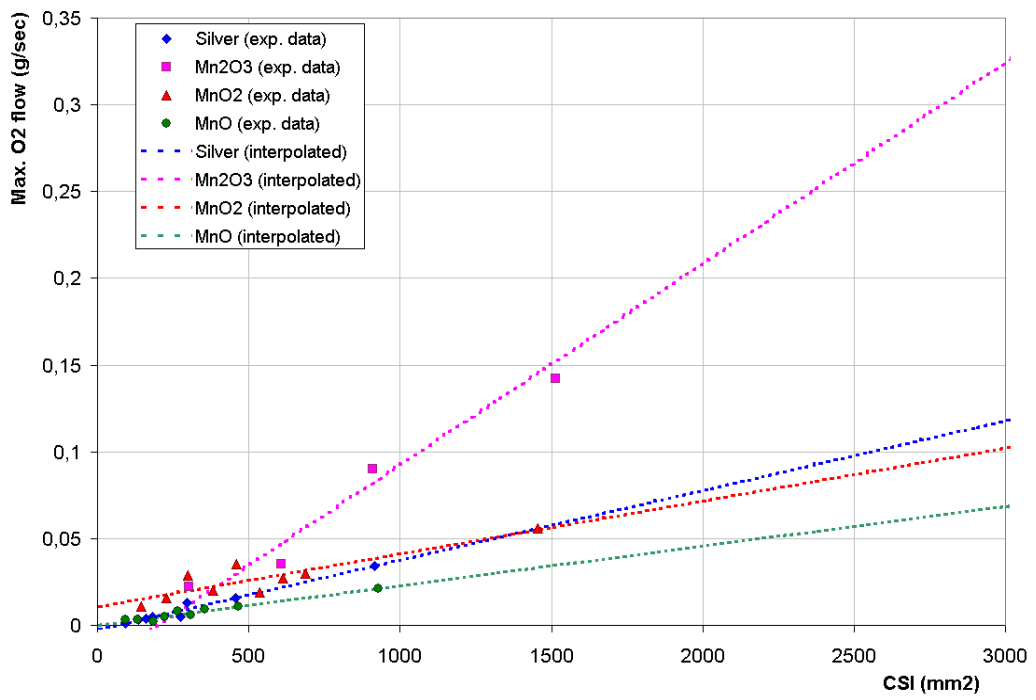

Figure 5. Maximum mass flow of exhaust oxygen, as a function of CSI, for four different powders.

\section{B. Evaluation of the reaction rate of different powders}

The experimental results presented in the last Section have also been used for the evaluation of the reaction rate of the different powders. To carry out this evaluation a first-order reaction has been considered, and the dependence of the reaction rate on the liquid mixture temperature has been assumed to follow the classical Arrhenius law:

$$
\dot{n}_{\mathrm{H}_{2} \mathrm{O}_{2}}^{(r)}=k \frac{n_{\mathrm{H}_{2} \mathrm{O}_{2}(l)}}{n_{\mathrm{H}_{2} \mathrm{O}_{2}(l)}+n_{\mathrm{H}_{2} \mathrm{O}(l)}} \quad, \quad k=A e^{-\frac{B}{R T_{r}}}
$$

The procedure used for evaluating the constants $A$ and $B$ for each experimental case has been the following:

1. Suitable initial guess values of $A$ and $B$ have been assumed; 
2. The time behavior of the liquid mixture temperature has been calculated for these initial values of $A$ and $B$ by numerically solving the system of 7 differential equations presented in Section II (a 3-rd order Runge-Kutta method has been used);

3. The evaluated temperature has been compared to the experimental one, and the mean square error between the two curves has been calculated;

4. The values of $A$ and $B$ have been iteratively modified by means of Powell gradiental method, in order to obtain a mean square percentage error minor than $10^{-3}$.

The results obtained for a particular case (MnO powder, $210 \mathrm{mg}$ mass) are presented in Figure 6. In this Figure the experimental data for the liquid mixture temperature (blue line) are compared to the numerical results obtained after the application of the above optimization technique for the evaluation of the reaction rate (red points). Good superposition between the two sets of data is evident.

The values of the reaction rate constant $k$ obtained by the application of this optimization technique are presented in Figures 7, 8 and 9. Figures 7 and 8 show, respectively, the value of $k$ as a function of the temperature for silver and $\mathrm{MnO}_{2}$ powders, for several values of CSI. Figure 9 , on the other hand, shows the value of $k$ for the different powders tested, as a function of CSI, for a given temperature (equal to $300 \mathrm{~K}$ ).

The main conclusions which can be drawn by the results obtained for the reaction rate are the following:

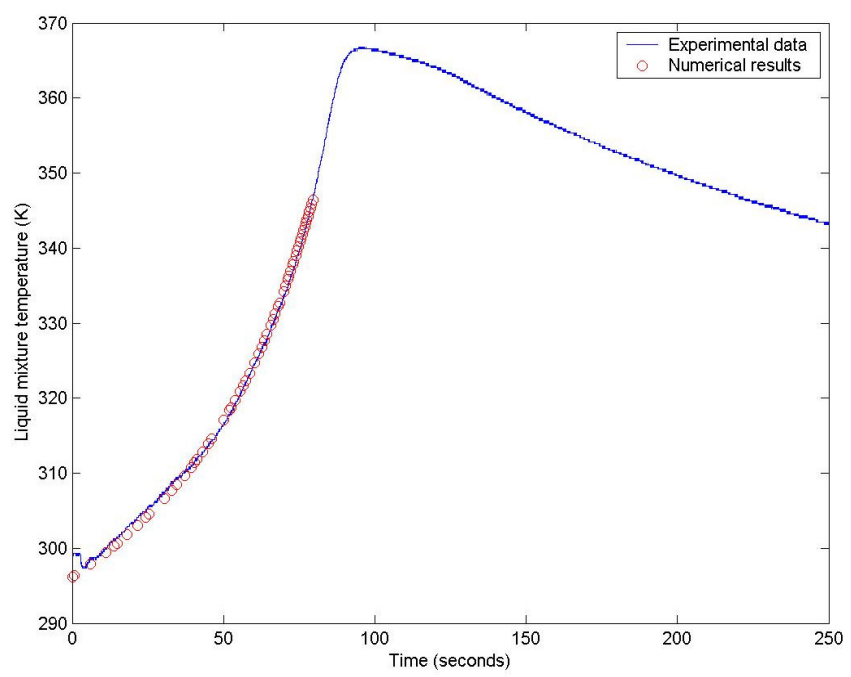

Figure 6. Comparison between the experimental and the analytical results for the liquid mixture temperature (MnO powder, mass $=210 \mathrm{mg}$ ).

It is confirmed that $\mathrm{Mn}_{2} \mathrm{O}_{3}$ is the most active catalyst powder, showing the highest value of the reaction rate at every temperature, followed by silver, $\mathrm{MnO}_{2}$ and $\mathrm{MnO}$.

- The assumed Arrhenius form for the reaction rate-temperature relation is confirmed to give a good correspondence with the experimental results. However, the experiments on silver at lower values of CSI seem to show a quasi-linear dependence of the reaction rate on the temperature, suggesting the possibility of a different order of reaction for this particular case (see Figure 7).

- The proposed method for the evaluation of the reaction rate starting from the experimental data obtained in test bench proved to be very effective. This technique could therefore be used for carrying out preliminary evaluations of the catalytic beds which will be used in the Alta-DELTACAT prototype thrusters, before testing their performance when installed in the real combustion chamber of the engine.

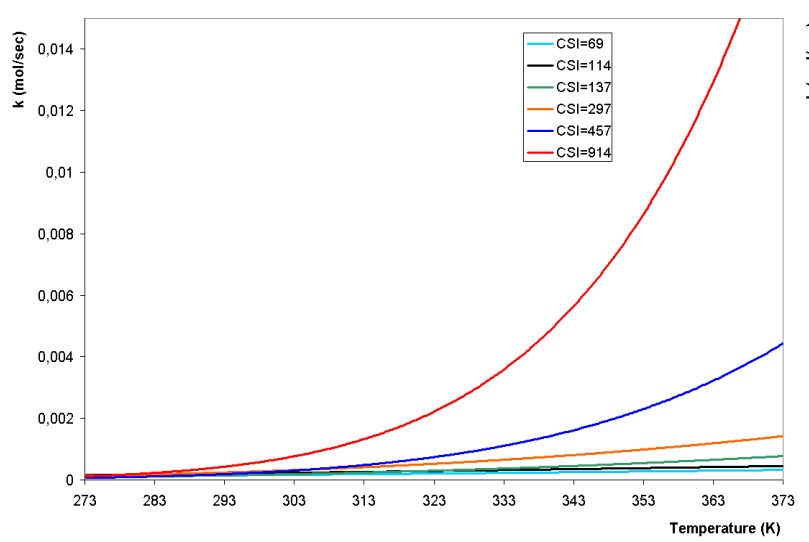

Figure 7. Reaction rate of silver powder, as a function of temperature, at different values of CSI.

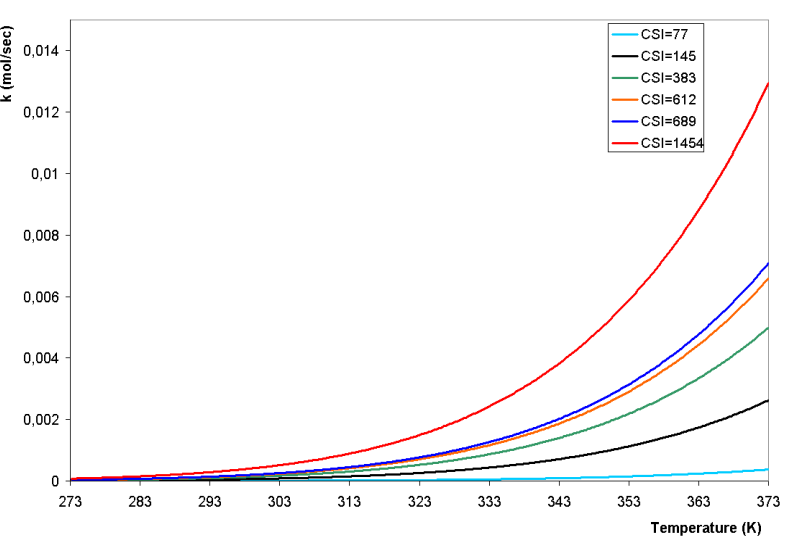

Figure 8. Reaction rate of $\mathrm{MnO}_{2}$ powder, as a function of temperature, at different values of CSI. 


\section{Tests on metallic wires}

This last set of experiments have been carried out on four different metallic wires with a diameter of $0.1 \mathrm{~mm}$ : Gold, Platinum, Palladium and Silver. In this case experiments have been conducted by both Alta and DELTACAT, in order to compare the results obtained and to collect a more complete amount of information.

Alta's experiments have been carried out on wires of $150 \mathrm{~mm}$ length, shaped in order to form coils with a diameter of $5 \mathrm{~mm}$. Four coils made of different metals have been placed on a stainless steel surface and $1 \mathrm{ml}$ of hydrogen peroxide solution has been dropped on each of them. Then, their ability to promote the decomposition reaction has been simply deduced by optical visualization of the phenomenon and pictures taken by the operators. Two different tests have been carried out: in the first the initial temperature of the stainless steel plate has been kept at room conditions ("cold" test), in the second it has been heated up to about $50^{\circ} \mathrm{C}$ before starting the experiment ("hot" test).

During the first phase of the "cold" test the silver coil showed an excellent activity, starting immediately to promote decomposition of the hydrogen peroxide. At the same time, platinum and palladium coils showed just a slight activity, while gold showed no activity at all. After about 5 minutes, while the catalytic activity of the silver coil was continuing to increase, some improvements in the activity of the platinum coil were observed. A slight improvement of the activity of the palladium coil was observed after 15 minutes. The first, weak, signals of activity of the gold coil were observed after about 20 minutes.

Slightly different results have been observed in the "hot" test. The gold coil, in this case, showed a better activity (greater than that of the palladium coil) since the beginning of the test, and its activity remained practically constant during the whole experiment (about 30 minutes). On the other hand, no significant differences with respect to the "cold" test have been observed in the behavior of the palladium coil. The initial activity of the platinum coil, in this test, has been observed to be better than that of the silver coil, but it remained constant during the experiment and tended to drop off after about 20 minutes, while the activity of the silver coil continuously increased during the test. Figure 10, as an example, shows the appearance of the silver coil in three different phases of the "cold" test.
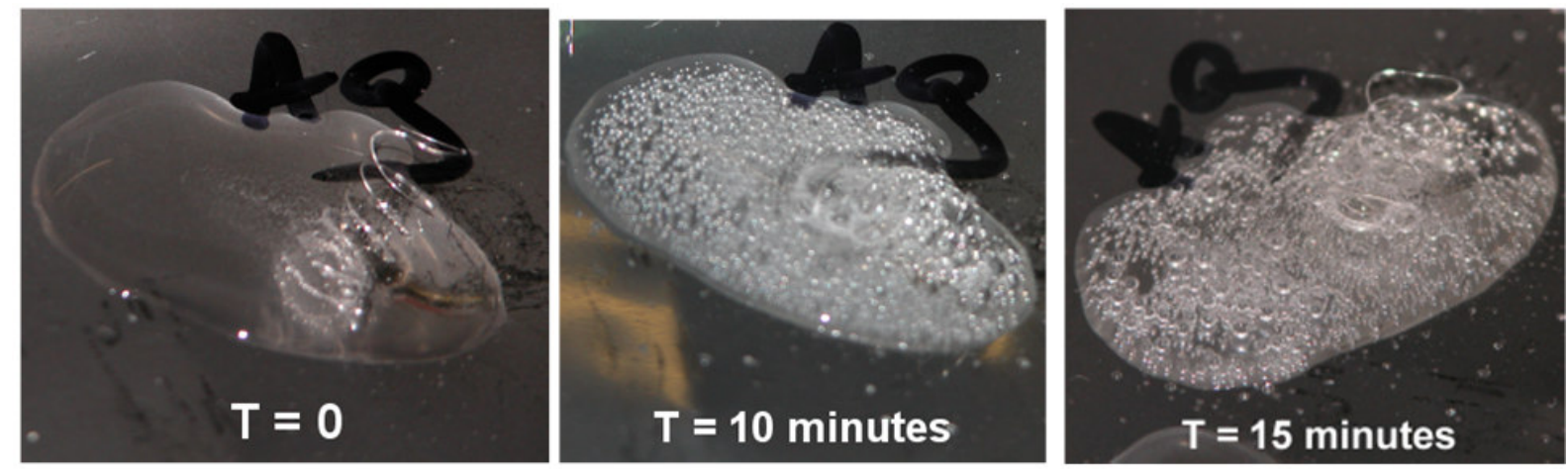

Figure 10. Appearance of the silver coil during the "cold" test.

Similarly, in DELTACAT's experiments two samples of each metallic wire have been prepared: the first one was a rod of $4 \mathrm{~mm}$ length, the second one was a coil of $12 \mathrm{~mm}$ length and $5 \mathrm{~mm}$ diameter. These samples have been brought into contact with hydrogen peroxide solutions at various concentrations and temperatures. The rods have been placed on a passivated stainless steel tray and two drops of the hydrogen peroxide solution have been placed on each rod such as to completely wet the rods. The coils have been dropped into pyrex test tubes and immersed in 10 grams of peroxide solution. As in the case of Alta's experiments, silver showed to be the best-performing catalytic 
material, while gold was the worst one. However, in some experiments the silver wire dissolved with time, indicating that its life as a catalyst could be limited.

\section{Conclusions and way forward}

The main conclusions which can be drawn by the set of experiments illustrated in the present paper are the following:

- Experiments on powders showed that $\mathrm{Mn}_{2} \mathrm{O}_{3}$ is the most effective catalytic material, followed by Silver and $\mathrm{MnO}_{2}$ (the last two show a very similar catalytic activity) and, as the less active material, MnO. In particular, the performance of $\mathrm{Mn}_{2} \mathrm{O}_{3}$ is significantly better than that of all the other tested materials.

- An effective technique for the determination of the decomposition reaction rate starting from liquid mixture temperature measurements during the tests has been developed and evaluated. This technique will be useful for the evaluation of the activity of the catalysts which will be developed for the prototype thrusters, before their installation and testing in the real engine.

- Visual tests on metallic wires showed that silver seems to be the most active catalytic metal, followed by platinum, palladium and gold. The performance of gold wires slightly improves in tests at higher temperatures. However, in some of the tests carried out by DELTACAT it has been noted that silver wire dissolved with time, indicating that its life as a catalyst could be limited.

At the present stage of the monopropellant thruster development carried out in the framework of the ESA-funded project, Alta and DELTACAT are considering catalytic beds based both on silver gauzes and manganese oxidecovered spheres. The last ones will be obtained by means of an impregnation/calcination technique on alumina substrates which is going to be developed by Alta in collaboration with the Chemistry Department of the University of Pisa. Platinum-covered alumina spheres, obtained by means of a similar deposition technique, are also being taken into account as a possible alternative solution.

\section{Acknowledgments}

The present Alta/DELTACAT joint activity on hydrogen peroxide monopropellant thrusters has been funded by ESA-ESTEC in the framework of the LET-SME program.

The authors would like to express their gratitude to Profs. Mariano Andrenucci, Fabrizio Paganucci and Renzo Lazzeretti of the Dipartimento di Ingegneria Aerospaziale, Università di Pisa, for their constant and friendly encouragement.

\section{References}

${ }^{1}$ Runckel J. F., Willis C.M., Salters Jr. L. B., 1963, "Investigation of Catalyst Beds for 98-Percent-Concentration Hydrogen Peroxide”, NASA TN D-1808, Langley Research Center, Hampton, Virginia.

${ }^{2}$ Willis C. M., 1960, "The Effect Of Catalyst-Bed Arrangement On Thrust Buildup And Decay Time For A 90 Percent Hydrogen Peroxide Control Rocket”, NASA TN D-516.

${ }^{3}$ Long M. R., Rusek J. J., 2000, “The Characterization of the Propulsive Decomposition of Hydrogen Peroxide”, AIAA paper n. 00-3683, 36th AIAA/ASME/SAE/ASEE Joint Propulsion Conference, Huntsville, Alabama.

${ }^{4}$ Ventura M., Mullens P., 1999, "The Use of Hydrogen Peroxide for Propulsion and Power", AIAA paper n. 99-2880, 35th AIAA/ASME/SAE/ASEE Joint Propulsion Conference, Los Angeles, California.

${ }^{5}$ Wernimont E., Ventura M., 2002, "Catalyst Bed Testing for Development of a 98\% Hydrogen Peroxide Procurement Specification”, AIAA paper n. 02-3852, 38th AIAA/ASME/SAE/ASEE Joint Propulsion Conference, Indianapolis, Indiana.

${ }^{6}$ Wu P.K., Fuller R.P., Morlan P.W., Ruttle D.W., Nejad A.S., Anderson W.E., 1999, "Development of a Pressure-Fed Rocket Engine Using Hydrogen Peroxide and JP-8", AIAA paper n. 99-2877, 35th AIAA/ASME/SAE/ASEE Joint Propulsion Conference, Los Angeles, California.

${ }^{7}$ Eloirdi R., Rossignol S., Chauveau M., Kappenstein C., Duprez D., Pillet N., 2000, "Design and Use of a Batch Reactor for Catalytic Decomposition of Different Monopropellants", AIAA paper n. 00-3553, 36th AIAA/ASME/SAE/ASEE Joint Propulsion Conference, Huntsville, Alabama.

${ }^{8}$ Ventura M., Wernimont E., 2001, “Advancements in High Concentration Hydrogen Peroxide Catalytic Beds”, AIAA paper n. 01-3250, 37th AIAA/ASME/SAE/ASEE Joint Propulsion Conference, Salt Lake City, Utah.

${ }^{9}$ Rusek J. J., 1996, "New Decomposition Catalysts and Characterization Techniques for Rocket-Grade Hydrogen Peroxide”, J. of Propulsion and Power, Vol.12, No. 3, pp. 574-580.

${ }^{10}$ Pirault-Roy L., Kappenstein C., Guerin M., Eloirdi R., Pillet N., 2002, "Hydrogen Peroxide Decomposition on Various Supported Catalysts Effect of Stabilizers”, J. of Propulsion and Power, Vol. 18, No. 6, pp. 1235-1241. 
${ }^{11}$ Bramanti C., Cervone A., d'Agostino L., 2005, "Assessment of the Propulsive Performance of Fuel Vapor Pressurized Hydrogen Peroxide-Ethane Rocket Engines”, XVIII Congresso Nazionale AIDAA, Volterra, Italy.

${ }^{12}$ Musker A. J., Roberts G., Chandler P., Grayson J., Holdsworth J., 2004, "Optimisation Study of a Homogeneously-Catalysed HTP Rocket Engine”, $2^{\text {nd }}$ International Conference on Green Propellants for Space Propulsion, Chia Laguna, Italy. 